\title{
PERSPECTIVAS DO PROCESSO DE EDUCAÇÃO EM SAÚDE PARA ESTUDANTES DE ESCOLAS PÚBLICAS: UMA EXPERIÊNCIA DE EXTENSIONISTAS
}

\author{
PERSPECTIVES ON THE HEALTH EDUCATION PROCESS FOR \\ PUBLIC SCHOOL STUDENTS: AN EXTENSIONIST EXPERIENCE
}

\author{
Sandriny Maria de Almeida Oliveira ${ }^{1}$ \\ Lara Bianca Soares Brandão ${ }^{2}$ \\ Diana Ísis Ribeiro Macêdo ${ }^{3}$ \\ Yuri de Almeida Oliveira ${ }^{4}$ \\ Nertan Ribeiro Batista ${ }^{5}$ \\ Marília Andreza da Silva Ferreira ${ }^{6}$
}

RESUMO: Por meio deste relato de experiência, pretende-se narrar e compartilhar as experiências e vivências de ensino-aprendizagem de estudantes de Enfermagem e Medicina na execução do projeto de extensão Bate-papo Saúde na Escola que foi desenvolvido na Universidade Federal de Campina Grande, campus Cajazeiras- PB. As ações realizadas ocorreram no primeiro semestre de $2019 \mathrm{com}$ alunos do município de Cajazeiras-PB com o intuito de desenvolver a discussão sobre as Infecções Sexualmente Transmissíveis (IST) e seus agravantes, além de partilhar conhecimento fundamentado nas teorias em saúde. Através de roda de conversa e dinâmicas foi estabelecido um tempo para dialogar e discutir, sendo possível realizar uma maior interação dos extensionistas com os estudantes do ensino fundamental e médio, permitindo uma troca de experiências e saberes. Os alunos foram muito participativos e demonstraram um grande interesse pela temática de modo que os

\footnotetext{
${ }^{1}$ Estudante do curso de Medicina da Universidade Federal de Campina Grande - UFCG, Cajazeiras PB (email: sandrinymaria23@hotmail.com).

${ }_{2}$ Estudante do curso de Medicina da Universidade Federal de Campina Grande - UFCG, Cajazeiras PB (email: byyab13@gmail.com).

${ }^{3}$ Estudante do curso de Medicina da Universidade Federal de Campina Grande - UFCG, Cajazeiras PB (email: dianaisis54@hotmail.com).

${ }^{4}$ Estudante do curso de Medicina da Universidade Federal de Campina Grande - UFCG, Cajazeiras PB (email: yuri.almeida2010@gmail.com).

${ }^{5}$ Estudante do curso de Medicina da Universidade Federal de Campina Grande - UFCG, Cajazeiras PB (email: nertan123@gmail.com).

${ }^{6}$ Orientadora. Técnica de Laboratório da Universidade Federal de Campina Grande - UFCG, Cajazeiras - PB; Biomédica Patologista Clínica; Mestre em Ciências Biológicas (email:marilia.andreza.masf@gmail.com).
} 
objetivos do projeto foram atendidos, demonstrando também, que as ações de promoção e educação em saúde são de extrema importância para informação e melhoria na qualidade de vida de jovens e adolescentes. É válido salientar que essas atividades contribuíram para mudanças relevantes no processo e percurso formativo dos extensionistas, desenvolvendo competências e habilidades potencializadoras de uma atitude ética, cidadã e transformadora diante de questões sociais e da organização dos serviços de saúde.

Palavras chave: Educação em saúde. Promoção da saúde. Infecções Sexualmente Transmissíveis. Ensino fundamental e médio.

ABSTRACT: Through this experience report, it is intended to narrate and share the teaching and learning experience of the medical students in the execution of the extension project calling Chat Health at School that was develop by Federal University of Campina Grande, at campus Cajazeiras-PB. The actions carried out took place in the first semester of 2019 with students from the municipality of Cajazeiras-PB in order to develop the discussion on Sexually Transmitted Infections (STI) and its aggravating factors, in addition to sharing knowledge based on health theories. Through conversation and dynamics, a time was established to dialogue and discuss, making it possible to have a greater interaction between extension workers and high school students, allowing for better learning. The students were very participative and showed a great interest in the theme. So, the objectives of the project were met, also demonstrating that the Health Promotion and Education actions are extremely important for information and improvement in the quality of life of young people and adolescents. It is worth noting that these activities contributed to relevant changes in the students' training process and path, developing skills and abilities that enhance an ethical, citizen and transformative attitude towards social issues and the organization of health services.

Keywords: Health Education. Health Promotion. Sexually Transmitted Infections. Primary and high school. 


\section{INTRODUÇÃO}

A educação é um dos pilares fundamentais para o desenvolvimento social, e a escola tem um papel fundamental na formação de cidadãos pensantes, principalmente quando se trata do binômio saúde e educação. Contudo, o sistema de ensino público, muitas vezes, carece de diretrizes que trabalhem de forma mais complexa a formação educacional, e por outro lado, limitam muitos assuntos ao plano informativo e disciplinar, o que impede que o estudante associe teoria e realidade social (LINS et. al, 2014).

O Programa Nacional de Saúde Escolar (PNSE) foi instituído em 1984 no ensino fundamental das escolas públicas com o objetivo de promover a saúde por meio de ações educativas, preventivas e curativas. Porém, essa promoção da saúde se desenrolou de modo disciplinador e centralizado na doença, o que evidencia o fracasso escolar em preparar o estudante para lidar e tomar decisões em relação às vivências em saúde. Nessa perspectiva, a educação em saúde nas escolas vem se desenvolvendo baseada em assuntos limitados e meramente informativos dentro de algumas disciplinas, campanhas pontuais sobre saúde sexual e ações em conjunto do Ministério da Saúde e da Educação nas escolas. Contudo, apesar da articulação intersetorial entre saúde e educação, as ações em saúde na escola ainda se restringem a um caráter higienista e medicalizante (MIRANDA, 2019).

As informações insuficientes e superficiais repassadas aos estudantes sobre determinadas doenças, faz com que estes sejam facilmente acometidos por elas, o que acentua as desigualdades e as mazelas sociais (LINS et. al., 2014). De acordo com os estudos de Campos et. al. (2017) sobre experiência em saúde em uma escola pública, foi observado que, para os adolescentes, saúde sexual significava usar preservativo e conhecer os tipos de Infecções Sexualmente Transmissíveis (ISTs), refletindo a pouca qualidade das informações aprendidas no ambiente escolar, além da falta de uma conversa mais descontraída sobre o assunto. 
Nesse contexto de fragilidades e deficiências das escolas públicas no ensino da educação em saúde, pelo pouco engajamento em discussões como ISTs e prevenção, são necessárias práticas que aproximem os jovens das vivências sociais, que os estimulem à troca de experiências de forma lúdica e natural e que os preparem para a tomada de decisões (LINS et. al, 2014). E nisso se enquadram os projetos de extensão universitária, que objetivam pôr em prática o que é aprendido na universidade e desenvolvê-lo fora dela de modo a contribuir positivamente com o crescimento social, como um instrumento de troca de experiências e saberes (BARBOSA et. al., 2019).

Segundo Rodrigues (2013), "a extensão universitária possui papel importante no que diz respeito às contribuições que pode trazer frente à sociedade". Os projetos de extensão possibilitam a democratização do saber de modo a ser um complemento ou suporte frente às necessidades sociais, principalmente no quesito educação em saúde (LINS, 2014). Por conta disso, o projeto de extensão Bate-Papo Saúde na Escola, foi idealizado com o intuito de aproximar a universidade da sociedade, especificamente dos estudantes do ensino médio da escola pública.

Com base no exposto, pretende-se narrar e compartilhar as experiências e as vivências de ensino-aprendizagem de estudantes de Enfermagem e Medicina na execução do projeto de extensão Bate-papo Saúde na Escola que foi desenvolvido na Universidade Federal de Campina Grande, campus Cajazeiras- PB, além de incentivar outros universitários a implementar esse tipo de projeto em suas universidades, pois o contato com outras visões de mundo e a responsabilidade de orientar outros estudantes adolescentes contribuem significativamente para uma boa formação acadêmica e social.

\section{METODOLOGIA}

A experiência relatada foi realizada por um grupo composto por dez extensionistas, estudantes de Enfermagem e de Medicina, e quatro orientadores da Universidade Federal de Campina Grande (UFCG), e ocorreu na cidade de 
Cajazeiras (PB), desde maio de 2019 até dezembro do mesmo ano. Esse projeto, antes de ser colocado em prática, teve sua aprovação deferida pela Pró-Reitoria de Pesquisa e Extensão da UFCG (PROPEX), que tem o intuito de pôr em vigor a Política Nacional de Extensão Universitária que vem sendo pactuada pelas Instituições de Ensino Superior integrantes do Fórum de Pró-Reitores de Extensão das Universidades Públicas Brasileiras.

O projeto de extensão Bate-papo Saúde na Escola foi composto por discentes de Medicina e de Enfermagem e foi caracterizado pelo seu intuito teórico-prático de troca de saberes e aprendizados, de forma preventiva e educativa sobre diversas doenças que acometem nossa sociedade com relevante frequência e que, muitas vezes, não são conhecidas devidamente pela maioria da população de classes sociais mais baixas. Por isso a intenção em buscar escolas da rede municipal de ensino, já que estas possuem, em sua maioria, alunos com essas características e assim, mais sujeitos às desigualdades sociais e suas mazelas, que incluem fragilidades no processo de prevenção, promoção em saúde e dificuldades no acesso ao conhecimento. O público alvo estava inserido na faixa etária de 13 a 18 anos de idade, e cursava entre o $8^{\circ}$ ano do ensino fundamental II e o $3^{\circ}$ ano do ensino médio, totalizando 150 alunos.

As ISTs escolhidas para a discussão foram as mais relevantes na saúde pública brasileira, como: AIDS, HPV, gonorreia, clamídia, sífilis e hepatites B e C. Os encontros foram organizados com a seguinte ordem: primeiro uma exposição dos conteúdos através de aulas e depois um momento com atividades dinâmicas e tira dúvidas para possibilitar a interação dos estudantes.

Uma característica desse projeto de extensão foi a utilização de tecnologias sociais leves e lúdicas para a produção de conhecimento e para o desenvolvimento do aprendizado daquelas crianças e adolescentes acerca do assunto. As estratégias utilizadas foram: roda de conversa com incentivo a exposição de dúvidas e sentimentos, gincanas do conhecimento, visitas técnicas em laboratórios da universidade, demonstração e atividades práticas com moldes anatômicos, métodos contraceptivos, explicações sobre exames como o colpocitologia oncótica cervical, colposcopia e diagnóstico laboratorial de ISTs (HIV, hepatites virais e sífilis). As 
ações foram planejadas com o intuito de propiciar espaço para a fala dos estudantes, através da exposição de dúvidas, medos e sentimentos.

A construção e desenvolvimento desse projeto foi através de gestão compartilhada entre extensionistas e orientadores. A equipe reuniu-se semanalmente para reciclagem do conhecimento acerca dos conteúdos, delineamento de estratégias, oficinas de capacitação técnica, estudo e discussão de artigos científicos e manuais institucionais. O planejamento das palestras e ações desenvolvidas foi feito com o intuito de encontrar alternativas de comunicação eficientes para o público-alvo.

O primeiro semestre foi utilizado somente para os treinamentos e planejamentos, enquanto no segundo foi buscada uma confirmação com as escolas que haviam sido pré-escolhidas antes da submissão do projeto, sendo estas as quais se adequassem aos objetivos especificados e, nesse ínterim, ser colocado em prática tudo que foi planejado.

\section{RESULTADOS E DISCUSSÃO}

O projeto Bate Papo Saúde na Escola culminou em intensa troca de experiências que abrangeu desde seu núcleo interno até os setores da sociedade que estavam incluídos nas metas traçadas. Para Incrocci e Andrade (2018), a palavra extensão está ligada, realmente, a esse fenômeno. Ela funciona como uma espécie de "ponte", seja entre a universidade e a sociedade, ou até mesmo entre os próprios extensionistas e seus orientadores.

Toda a estrutura de apresentação às escolas foi confeccionada, tendo em vista o objetivo inicial do projeto: possibilitar um verdadeiro bate-papo que contribua com a formação social dos alunos da rede pública, de modo a orientá-los sobre ISTs e prevenção. Ao mesmo tempo, foi oferecida aos membros do projeto a oportunidade de conhecer outras realidades sociais e pôr em prática o aprendizado da sala de aula, acontecimento proporcionado pela manutenção de uma porta aberta entre a universidade e a sociedade (INCROCCI; ANDRADE, 2018). 
Iniciada a conversa, ministrada por representantes extensionistas, o debate era guiado para o esclarecimento dos principais tabus que envolvem assuntos como sexualidade, Infecções Sexualmente Transmissíveis (ISTs), métodos preventivos, reconhecimento da necessidade de buscar ajuda profissional, entre outros. A equipe se preocupou em mostrar-se completamente aberta às dúvidas, sejam elas quais fossem, e em se sobrepor aos desafios postos para a abordagem da temática, que decorrem de sua inerente complexidade, visto que pode envolver diferentes percepções, padrões culturais e visões de mundo (GAVA; VILLELA, 2016).

Dessa forma, para cada encontro foi construída uma abordagem, julgada como modalidade mais eficaz para manter os estudantes atentos à explanação e à vontade para se expressarem. Dentre os temas debatidos, que foram: Infecções sexualmente transmissíveis (ISTs) - como AIDS, HPV, gonorreia, clamídia, entre outras, os extensionistas elaboraram quadros como "mitos e verdades", tira-dúvidas, imagens com sinais característicos de algumas doenças, slides demonstrativos de técnicas diagnósticas, como o teste rápido para sífilis, seguido do método VDRL e FTA-ABS, por exemplo.

O diferencial das apresentações ministradas pelo projeto Bate Papo Saúde na Escola - relatado, inclusive, pelos próprios estudantes, se deu na explicação de protocolos de saúde, por meio de linguagem simplificada e acessível. Tal feito foi capaz de atenuar o possível estranhamento inicial de jovens e adolescentes em idade escolar, frente a debates e campanhas de conscientização sexual, por exemplo.

Esse fato se deve, em grande parte, à construção da educação infantil e juvenil. Para Carvalho et al. (2017), o processo educativo da formação de jovens possui dificuldades nesse cenário. É preciso que haja adequação do orador com relação ao público alvo, promovendo um ambiente encorajador para levantar questões. Todos devem ser considerados como seres sexuais, com acesso a material informativo sobre a sexualidade e possibilidade de diálogo.

Com efeito, os participantes manifestaram dúvidas que tinham há muito tempo, mas que alegavam constrangimento em falar sobre o assunto com adultos ou profissionais da saúde. Essa dificuldade também foi reforçada pelo déficit educacional das escolas, sobretudo na rede pública, em que os temas de ciências 
da saúde são abordados com superficialidade, se abordados, ou de forma pouco lúdica. Apesar do projeto de lei $\left(P L n^{\circ}\right.$ 120/2019) que disciplina a matéria de Educação Sexual nas escolas públicas de ensino básico e nível médio ter sido em 2019, há dificuldade por parte dos docentes em ministrar alguns conteúdos, e resistência dos discentes em discuti-los de forma produtiva (GARCIA, 2015).

A equipe extensionista também se preocupou em conversar sobre as notícias televisivas e virtuais que abordam tais temáticas. Sempre que possível, manchetes foram incluídas quando lembravam a relevância social das doenças abordadas, como oportunidade, também, de explicar alguns termos e incluir dicas de prevenção no assunto.

Cientes de que a maioria dos jovens e adolescentes se encontram nas redes sociais, durante as apresentações buscou-se fazer referência à importância de analisar as fontes de qualquer notícia em saúde, demonstrando, também, alguns sites científicos com publicações acessíveis que podem ser consultados sempre que necessário.

Agindo nessa vertente, o Projeto Bate-Papo Saúde na Escola esteve presente também nas redes, por meio de perfil criado no Instagram, o qual foi utilizado para postagens sobre saúde, esclarecimentos e debates com os seguidores. As publicações eram feitas de forma direta e informativa, visando interagir com o público, ao mesmo tempo que repassa informações, utilizando enquetes, por exemplo. Essa iniciativa se deu, pelo entendimento da equipe, sobre a presença constante das redes sociais na rotina dos jovens em idade escolar.

O fenômeno das redes sociais é marcante e inquestionável, com a adesão majoritária de jovens em idade de ensino fundamental e médio. Apesar disso, muito se discute, em cenário atual, sobre a atuação do jovem como consumidor de conteúdo geral versus produtor de conteúdo ou público alvo específico de informações construtivas no sentido educacional (ROSADO, 2015). Dessa forma, o uso das redes sociais no projeto veio contribuir como espaço de construção de conhecimento através do compartilhamento de informações, usando a internet como ambiente de disseminação de forma acessível e plural.

Além disso, em algumas ocasiões, a equipe buscou trazer os estudantes até o laboratório da UFCG, conforme pode ser visto na fotografia 1. Esses encontros 
foram extremamente benéficos, pois possibilitaram aos estudantes um contato direto com o ambiente da universidade, bem como com materiais de estudo em pesquisas científicas, gerando oportunidade de ensinamento sobre temas que despertaram curiosidade.

Fotografia 1 - Estudantes e extensionistas em laboratório da UFCG.

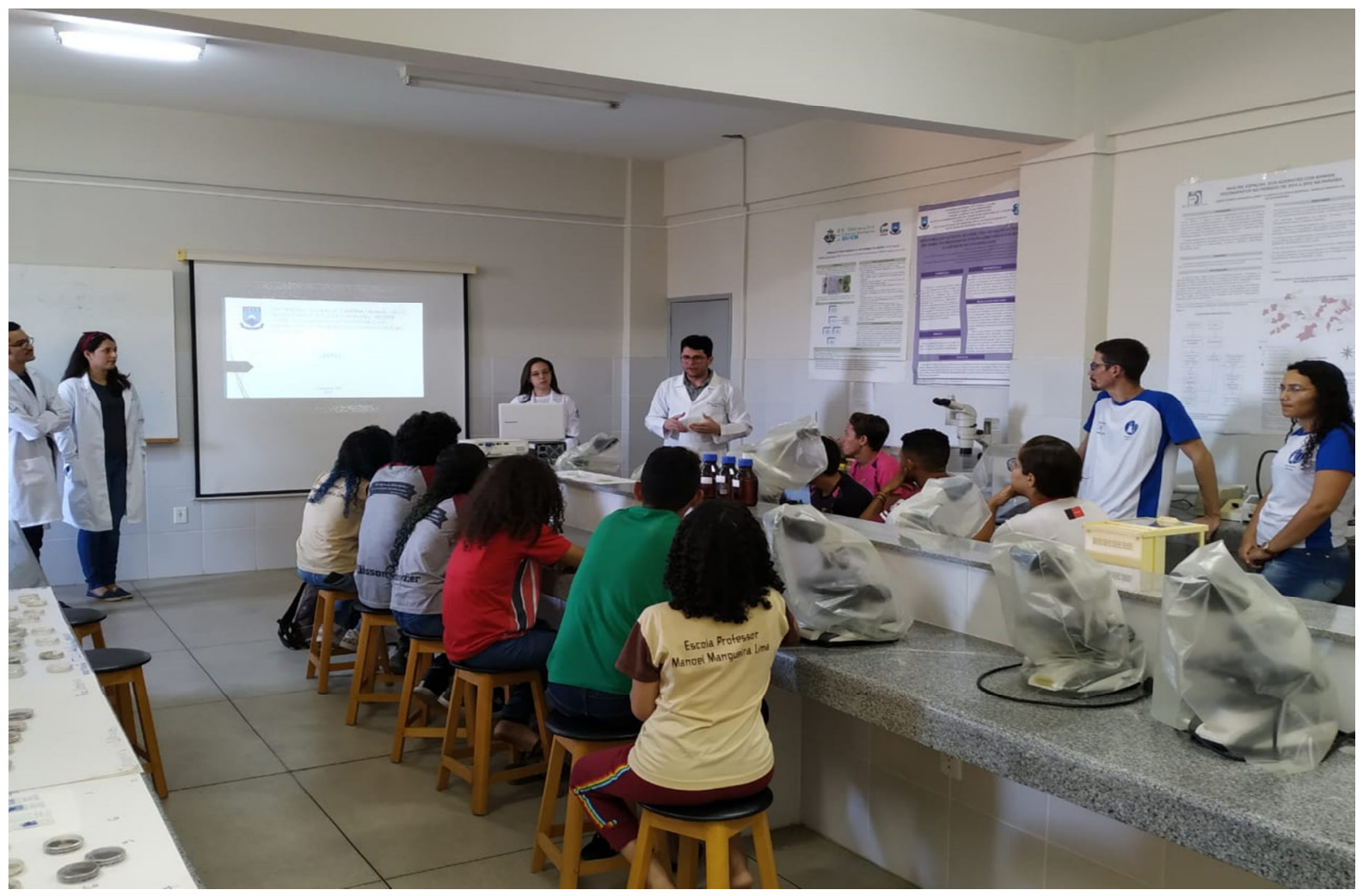

Fonte: Acervo dos extensionistas.

Por meio dessas ações, buscou-se impactar os estudantes de modo a despertar a atenção para o ensino superior, possibilitar acesso a materiais específicos para o diagnóstico e tratamento de doenças e tirar dúvidas acerca do ambiente da universidade e dos cursos da saúde, levantadas pelos próprios estudantes. Em contrapartida, os extensionistas puderam ter acesso às demandas expostas, sendo de alta relevância para sua formação profissional e posterior atuação na sociedade. 
De acordo com Sampaio (2011), o contato com o ambiente universitário é de extrema vantagem, pois esses jovens (oriundos da rede pública) tendem a carregar uma história familiar de escolarização incompleta, precária e fragmentada, que poderia favorecer entre eles certa resistência à cultura escolar, reforçada pelas dificuldades que enfrentam para o ingresso no ensino superior. Nesse contexto, a aproximação proporcionada pelo projeto, bem como as demonstrações realizadas, foram ferramentas importantes na familiarização com o ensino superior.

Dessa forma, ao finalizar o ciclo de apresentações nas escolas préselecionadas, a equipe do projeto Bate-Papo Saúde na Escola concluiu que os objetivos iniciais foram alcançados e ultrapassados. Todos os assuntos listados teriam sido amplamente discutidos e plenamente compreendidos pelo público-alvo, segundo relato destes.

Para os extensionistas, os encontros foram de muito aprendizado. Considerando que os profissionais da saúde possuem uma rotina, em sua maioria, voltada para o contato com o público, é essencial a proximidade às demandas sociais, desde a formação. Para que as apresentações fossem concluídas, foram necessários vários encontros para trabalhar as principais dificuldades do projeto, entre elas, simplificar a linguagem científica atrelada aos processos de saúde e doença, de modo a manter a integridade da informação e o entendimento dos jovens.

Ademais, para que o objetivo geral fosse cumprido, foi preciso construir um material que alcançasse e atraísse o público, para que as atividades planejadas fossem realizadas com o engajamento necessário. Dessa forma, os extensionistas se empenharam por meio de pesquisas e debates, a fim de manter o ritmo de ensino lúdico e acessível, buscando, também, manter uma postura amigável, transparecendo confiança para os ouvintes se posicionarem. Esse processo conferiu considerável amadurecimento aos universitários, com aprendizados nas áreas de pesquisa, ensino e oratória.

Para David (2015), a relação entre a universidade e a sociedade deve ser transformadora. Dessa forma, a extensão foi protagonista na transformação ocorrida entre os indivíduos envolvidos na realização deste projeto. Todos os encontros foram de extremo proveito para construção profissional dos extensionistas, bem 
como o conhecimento repassado teve impacto positivo na construção pessoal e social do público-alvo, que pôde ser avaliado através de auto relatos.

Por fim, é de se destacar que algumas dificuldades apareceram durante a execução, principalmente interdição e realocação do espaço físico da escola parceira do projeto, o que acabou por comprometer as atividades propostas para algumas escolas no ano em curso. As dificuldades surgidas na execução do projeto, de certa maneira, nos obrigaram a fazer adequações ao projeto, mas sem comprometer os objetivos e os resultados a serem alcançados.

\section{CONCLUSÃO}

Conclui-se que a extensão universitária contribuiu na formação dos acadêmicos de Medicina e de Enfermagem através da oportunidade de interação, reflexão e compreensão acerca de outras realidades, troca de saberes entre os diferentes atores sociais envolvidos e desenvolvimento de habilidades $e$ competências voltadas para a comunicação e assistência em saúde.

A comunidade escolar pôde esclarecer dúvidas com profissionais de saúde, desmistificar tabus e refletir sobre a necessidade da adoção de comportamentos pautados pela prevenção em suas práticas sexuais.

Neste espaço houve a possibilidade de aprimorar a interação professor-aluno, que ensinam e enriquecem, com suas experiências de vida, os futuros profissionais da área da saúde. Estas atividades também fomentaram o interesse pela pesquisa sobre a saúde da população em relação às ISTs nos próprios extensionistas, reforçando a indissociabilidade do eixo ensino, pesquisa e extensão que são o tripé da Universidade. Ressalta-se a necessidade de investimentos e ampliação de ações voltadas para a atenção em saúde de populações vulneráveis no campo de doenças transmissíveis e um olhar diferenciado para os estudantes de escolas públicas do Brasil. 


\section{REFERÊNCIAS BIBLIOGRÁFICAS}

ARRUDA-BARBOSA, L. et al. Extensão como ferramenta de aproximação da universidade com o ensino médio. Cadernos de Pesquisa, São Paulo, v. 49, n.174, p. 316-327, dez. 2019. Disponível em: http://www.scielo.br/scielo.php?script=sci_arttext\&pid=S0100$15742019000400316 \&$ Ing=en\&nrm=iso. Acesso em:19 jul.2020.

CAMPOS, H. M. et al. Direitos humanos, cidadania sexual e promoção de saúde: diálogos de saberes entre pesquisadores e adolescentes. Saúde debate, Rio de Janeiro, v. 41, n. 113, p. 658-669, abr. 2017. Disponível em: http://www.scielo.br/scielo.php?script=sci_arttext\&pid=S0103-

$11042017000200658 \&$ Ing=pt\&nrm=iso. Acesso em: 19 jul. 2020.

CARVALHO, C. P. et. al. Conhecimentos sobre sexualidade: construção e validação de um instrumento de avaliação para adolescentes em contexto escolar. Revista Portuguesa de Educação, [S.L.], v. 30 , n. 2, p. 249, 7 dez. 2017. University of Minho. Disponível em: http://www.scielo.mec.pt/pdf/rpe/v30n2/v30n2a12.pdf. Acesso em: 23 jul. 2020.

DAVID, C. M. et al. Desafios contemporâneos da educação [online]. São Paulo: Editora UNESP; São Paulo: Cultura Acadêmica, 2015. Desafios contemporâneos collection, 370 p. ISBN 97885-7983-622-0. Disponível em: https://static.scielo.org/scielobooks/zt9xy/pdf/david9788579836220.pdf. Acesso em: 24 jul 2020.

GARCIA, O. A. Marcas da experiência na formação docente em gênero e diversidade sexual: um olhar sobre o curso "Gênero e diversidade na escola" (GDE). 2015. Dissertação (Mestrado em Educação) - Faculdade de Educação, Universidade de São Paulo, São Paulo, 2015. Acesso em: 26 jul 2020.

GAVA, T.; VILLELA, W. V. Educação em Sexualidade: desafios políticos e práticos para a escola. Sexualidad, Salud y Sociedad (Rio de Janeiro), Rio de Janeiro, n. 24, p. 157-171, dez. 2016. FapUNIFESP (SciELO). Disponível em: https://www.scielo.br/scielo.php?script=sci_arttext\&pid=S1984-64872016000300157\#B5. Acesso em: 23 jul. 2020.

INCROCCI, L. M. M. C.; ANDRADE, T. H. N. O fortalecimento da extensão no campo científico: uma análise dos editais proext/mec. Sociedade e Estado, [S.L.], v. 33, n. 1, p. 187-212, abr. 2018. FapUNIFESP (SciELO). Disponivel em: https://www.scielo.br/pdf/se/v33n1/0102-6992-se33-01-187.pdf. Acesso em: 23 jul. 2020.

LINS, L. et al. Extensão universitária e inclusão social de estudantes do ensino médio público. Trabalho, educação e saúde, Rio de Janeiro, v. 12, n. 3, p. 679-694, dez. 2014. Disponível em: http://www.scielo.br/scielo.php?script=sci_arttext\&pid=S1981-

77462014000300679\&Ing=en\&nrm=iso. Acesso em: 20 jul. 2020.

MIRANDA, D. N.; MARCH, C.; KOIFMAN, L. Educação e saúde na escola e a contrarreforma do ensino médio: resistir para não retroceder. Trabalho, educação e saúde, Rio de Janeiro, v.17, n.2, jun. 2019. Disponível em: http://www.scielo.br/scielo.php?script=sci_arttext\&pid=\$198177462019000200401\&lng=en\&nrm =iso. Acesso em: 20 jul. 2020.

ROSADO, L. A. S.; TOMÉ, V. M. N. As redes sociais na internet e suas apropriações por jovens brasileiros e portugueses em idade escolar. Revista Brasileira de Estudos Pedagógicos, [S.L.], v. $96, \quad$ n. 242, p. 11-25, abr. 2015. Disponível em: http://www.scielo.br/scielo.php?script=sci_arttext\&pid=S2176$66812015000100011 \&$ Ing=en\&nrm=iso. Acesso em: 22 jul. 2020. 
Perspectivas do Processo de Educação em Saúde Para Estudantes de Escolas Públicas: Uma Experiência de Extensionistas

SAMPAIO, S. M. R. Entre a escola pública e a universidade: longa travessia para jovens de origem popular. In: Observatório da vida estudantil: primeiros estudos [online]. Salvador: EDUFBA, 2011, p. 27-51. ISBN 978-85-232-1211-7. Disponível em: http://books.scielo.org/id/n656x/pdf/sampaio-9788523212117-03.pdf. Acesso em:22 jul. 2020. 